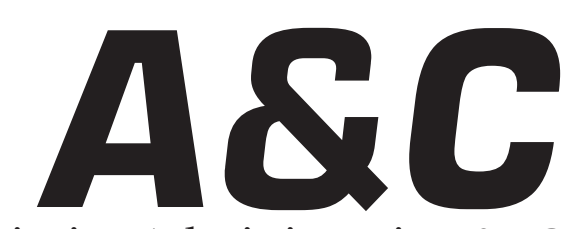

Revista de Direito Administrativo \& Constitucional

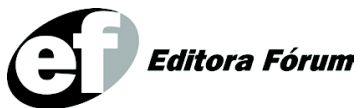

ISSN 1516-3210

A\&C R. de Dir. Administrativo e Constitucional Belo Horizonte ano 8 n. 31 p. 1-272 jan./mar. 2008 


\section{A\&C - REVISTA DE DIREITO ADMINISTRATIVO E CONSTITUCIONAL}

IPDA

Instituto Paranaense

de Direito Administrativo

Direção Geral

Romeu Felipe Bacellar Filho

Direção Editorial

Paulo Roberto Ferreira Motta

Direção Executiva

Emerson Gabardo

Conselho de Redação

Edgar Chiuratto Guimarães

Adriana da Costa Ricardo Schier

Célio Heitor Guimarães

\section{Conselho Editorial}

Adilson Abreu Dallari

Alice Gonzáles Borges

Carlos Ari Sundfeld

Carlos Ayres Britto

Carlos Delpiazzo

Cármen Lúcia Antunes Rocha

Celso Antônio Bandeira de Mello

Clèmerson Merlin Clève

Clóvis Beznos

Enrique Silva Cimma

Eros Roberto Grau

Fabrício Motta

Guilhermo Andrés Muñoz (in memoriam)

Jaime Rodríguez-Arana Muñoz

Jorge Luís Salomoni

José Carlos Abraão
José Eduardo Martins Cardoso
José Luís Said
José Mario Serrate Paz
Juan Pablo Cajarville Peruffo
Juarez Freitas
Julio Rodolfo Comadira
Luís Enrique Chase Plate
Lúcia Valle Figueiredo
Manoel de Oliveira Franco Sobrinho
(in memoriam)
Marçal Justen Filho
Marcelo Figueiredo
Márcio Cammarosano
Maria Cristina Cesar de Oliveira

Nelson Figueiredo

Odilon Borges Junior

Pascual Caiella

Paulo Eduardo Garrido Modesto

Paulo Henrique Blasi

Paulo Neves de Carvalho (in memoriam)

Paulo Ricardo Schier

Pedro Paulo de Almeida Dutra

Regina Maria Macedo Nery Ferrari

Rogério Gesta Leal

Rolando Pantoja Bauzá

Sérgio Ferraz

Valmir Pontes Filho

Yara Stropa

Weida Zancaner

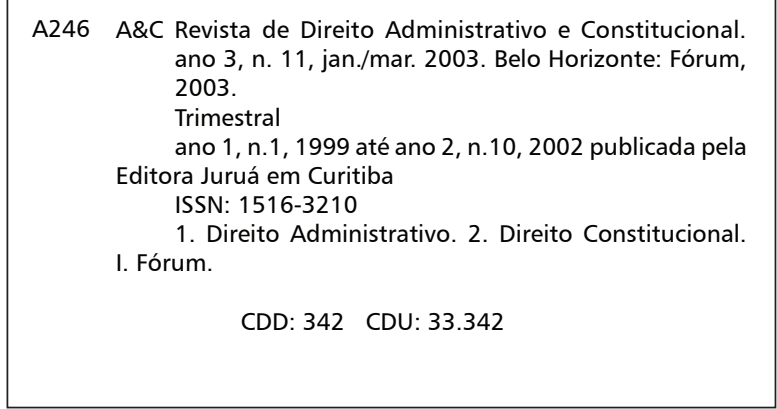

(c) Editora Fórum Ltda. 2008

Todos os direitos reservados. É proibida a reprodução total ou parcial, de qualquer forma ou por qualquer meio eletrônico ou mecânico, inclusive através de processos xerográficos, de fotocópias ou de gravação, sem permissão por escrito do possuidor dos direitos de cópias (Lei $n^{\circ}$ 9.610, de 19.02.1998).

Editora Fórum Ltda.

CEP 30130-007 - Belo Horizonte/MG - Brasil

Tel.: 08007043737

Internet: www.editoraforum.com.br

e-mail: editoraforum@editoraforum.com.br
Av. Afonso Pena, 2770 - 15\%/16 andar - Funcionários

Editor responsável: Luís Cláudio Rodrigues Ferreira

Coordenação editorial: Olga M. A. Sousa

Projeto gráfico e diagramação: Luis Alberto Pimenta

Revisoras: Carolina Rocha

Lourdes Nascimento

Pesquisa jurídica: Fátima Ribeiro - OAB/MG 74868

Bibliotecárias: Fernanda de Paula Moreira

Leila Aparecida Anastácio - CRB 2513 - 6ª região

Os conceitos e opiniões expressas nos trabalhos assinados são de responsabilidade exclusiva de seus autores.

Impressa no Brasil / Printed in Brazil

Distribuída em todo o Território Nacional 


\title{
El Marco Constitucional del Derecho Administrativo en Colombia
}

\author{
Libardo Rodríguez Rodríguez \\ Profesor de Derecho Administrativo. Ex-Consejero de Estado de Colômbia.
}

Palabras clave: Derecho administrativo colombiano. Derecho constitucional. Constitución colombiana

Índice: I Introducción - II Las Relaciones entre el Derecho Administrativo y el Derecho Constitucional - III La Proyección del Modelo de Estado en el Conjunto del Derecho Administrativo - IV Principales Principios y Criterios Constitucionales que afectan al Derecho Administrativo - V Las Instituciones del Derecho Administrativo que han sido elevadas a rango constitucional VI Conclusiones

\section{Introducción}

La vida institucional de Colombia, como Estado, comenzó con la declaratoria de Independencia de la Corona Española, producida el 20 de julio de 1810. A partir de ese momento se han expedido diversas constituciones políticas, de acuerdo con las cuales pueden identificarse tres etapas de la vida institucional de nuestro país:

Una primera etapa, que podemos denominar de estructuración del Estado, caracterizada por la inestabilidad y cierta anarquía institucional, que produjo como resultado la expedición de un buen número de constituciones que reflejaban la preocupación por la búsqueda de una organización política que expresara el querer de la mayoría de los integrantes de la nación. Esta etapa corresponde a la mayor parte del siglo XIX, durante el cual se expidieron inicialmente constituciones provinciales como la de Cundinamarca, de 1811; la de Tunja, de 1811; la de Antioquia, de 1812; la de Cartagena de Indias, igualmente de 1812; de nuevo la de Cundinamarca, de 1812; la de Mariquita, de 1815; la de Pamplona, de 1815, y la de Neiva de 1815. Otras que pretendían gobernar territorios más extensos de los que posteriormente se decantaron como integrantes del Estado actual, como fue el caso de las Constituciones de la Gran Colombia, de 1821 y 1830. Y otras, finalmente, que se caracterizaron por ser el resultado de la lucha entre centralistas y federalistas, que propugnaban por imponer el modelo de Estado unitario o federal, como fue el caso de las Constituciones de 1832, 1843, 1853, 1858 y 1863.

Una segunda etapa que corresponde a los casi cien años de vigencia de la Constitución de 1886, con varias reformas producidas entre ese 
año y 1991, que reflejan una vida institucional más estable, alrededor del modelo de Estado unitario, con centralización política y descentralización administrativa. ${ }^{1}$

Finalmente, una tercera etapa que comienza con la expedición de la Constitución de 1991, caracterizada por la preocupación de introducir a la vida institucional colombiana las expresiones más contemporáneas de la organización y el funcionamiento de los Estados actuales.

Dentro de este marco histórico constitucional, este trabajo pretende mostrar la forma como han evolucionado las relaciones del derecho administrativo con el derecho constitucional en Colombia.

\section{Las Relaciones entre el Derecho Administrativo y el Derecho Constitucional}

Puede afirmarse que las relaciones entre el derecho administrativo de un país determinado y el derecho constitucional de ese mismo país son casi naturales. Como lo hemos expresado en nuestro texto de Derecho Administrativo, "las relaciones más estrechas del derecho administrativo se presentan con el derecho constitucional, pues, en primer lugar, ambos hacen parte del derecho público y tienen por objeto el estudio de la administración, hasta el punto que es difícil separar claramente sus respectivos campos de acción.

"En segundo lugar, puede afirmarse que el derecho constitucional es la fuente principal del derecho administrativo, es decir, que éste es una consecuencia de aquél. Así, el derecho constitucional establece los principios fundamentales para la organización y la actividad de la administración y el derecho administrativo los desarrolla. Por ejemplo, la Constitución Política establece que en materia de organización administrativa encontramos, entre otros, al presidente de la república, los ministros, los directores de departamentos administrativos, los departamentos y municipios, pero es mediante el derecho administrativo por el que conocemos en detalle estas autoridades y organismos. Igualmente, la Constitución consagra los principios que rigen el control de las autoridades administrativas, pero es el derecho administrativo el que los desarrolla y les da aplicación práctica”. ${ }^{2}$

Si buscamos con mayor precisión el alcance de esa relación en el caso

\footnotetext{
Para consultar el texto de las diversas constituciones provinciales y nacionales que han existido en la historia de Colombia, así como de sus reformas, véase a DIEGO URIBE VARGAS, las constituciones de Colombia, vols. II y III, 2. ed., Madrid, Ediciones Cultura Hispánica - Instituto de Cooperación Iberoamericana, 1985.

2 LIBARDO RODRÍGUEZ RODRÍGUEZ, Derecho administrativo - General y colombiano, 14. ed., Bogotá, Editorial Temis, 2005, p. 31.
}

A \& C R. de Dir. Administrativo \& Constitucional, Belo Horizonte, ano 8, n. 31, p. 124-149, jan./mar. 2008 
de Colombia, podemos partir de una visión general de los grandes temas contenidos en las diferentes constituciones colombianas.

$\mathrm{Al}$ respecto, si utilizamos las etapas que hemos identificado en la introducción de este trabajo y las constituciones expedidas durante cada una de ellas, podemos constatar lo siguiente:

En relación con las constituciones expedidas durante la etapa de estructuración del Estado, es decir, durante la mayor parte del siglo XIX, su contenido está determinado fundamentalmente por el tema de la organización del Estado y el de los derechos políticos de los ciudadanos. Sin embargo, durante esta etapa, si bien obviamente el desarrollo de los principios y reglas constitucionales implicaba la expedición de normas de contenido administrativo en cuanto regulaban la organización y funcionamiento de la administración pública, como lo hemos hecho ver en otro escrito, durante esta etapa no se puede hablar propiamente de derecho administrativo en cuanto esta disciplina era prácticamente desconocida en el medio colombiano, tanto académica como judicialmente. ${ }^{3}$

Respecto de la Constitución de 1886, lo primero que debe hacerse notar es que ella no solo reinstauró la institución del Consejo de Estado, que había sido creado por Bolívar en 1817 a imagen y semejanza del Consejo de Estado creado por Napoleón en Francia en 1799, pero que había tenido una existencia muy inestable y apenas como órgano asesor del ejecutivo, sino que previó la posibilidad de que el legislador creara la jurisdicción administrativa especializada en la solución de las controversias en que fuera parte el Estado y ordenó que, en caso de que el legislador concretara esa creación, el Consejo de Estado sería el tribunal supremo de la misma. Esta previsión constitucional se concretó en 1913 con la expedición del primer código contencioso administrativo y la creación de la jurisdicción contencioso administrativa, la cual comenzó a funcionar efectivamente en 1914, bajo la dirección del Consejo de Estado como tribunal supremo de la misma. ${ }^{4}$

Si se tiene en cuenta, además, que la creación de la jurisdicción con-

\footnotetext{
3 Véase a LIBARDO RODRÍGUEZ RODRÍGUEZ, "Un siglo de derecho administrativo en Colombia", en El derecho público a comienzos del siglo XXI. Estudios en homenaje al profesor Allan R. Brewer Carías, t. II, Madrid, Editorial Civitas, 2003, p. 1335 y ss.

4 Sobre la creación y evolución de la institución del Consejo de Estado y de la jurisdicción de lo contencioso administrativo en Colombia, véase a LIBARDO RODRíGUEZ RODRÍGUEZ, "El Consejo de Estado de Colombia: una institución bolivariana", en Estudio, Órgano de la Academia deHistoria de Santander, año LXVI, núm 327, Bucaramanga, enero de 2002, p. 7 y ss.
} 
tencioso administrativa se produjo en Colombia en ese momento como un reflejo del éxito que había tenido el Consejo de Estado francés durante el siglo XIX, como creador pretoriano de un nuevo ordenamiento jurídico especializado para controlar el ejercicio de la función administrativa del Estado, se entenderá fácilmente que la jurisdicción administrativa colombiana comenzó a actuar también bajo la filosofía que inspiraba ese ordenamiento jurídico especial para la administración pública, que se consideraba como un desarrollo inmediato de las normas que consagraba la Constitución para regular la organización y el funcionamiento de esa función administrativa.

Debe anotarse también que, en términos generales, los temas contenidos en la Constitución Política de 1886 eran similares a los de las Constituciones anteriores, referidos a la organización y funcionamiento del Estado, a través de las ramas u órganos del poder público tradicionales, de origen montesquiano, junto con los derechos y deberes que regulaban las relaciones entre las autoridades y los gobernados, añadiendo algunas disposiciones generales relacionadas con la hacienda pública. ${ }^{5}$ Sin embargo, a pesar de esa similitud en cuanto a los temas constitucionales, en esta etapa sí podemos hablar ya de una estrecha relación entre el derecho constitucional y el administrativo, en la medida en que la existencia de la jurisdicción especial contencioso administrativa y la consecuente aplicación de la filosofía que propugnaba por un régimen jurídico especial para la administración del Estado, implicaban que el desarrollo de las disposiciones constitucionales se hacía dentro del marco de esa filosofía, lo cual fue produciendo progresivamente, como resultado, la configuración y consolidación del derecho administrativo colombiano.

Finalmente, la Constitución de 1991 amplió de manera importante la temática de su contenido, especialmente en su parte dogmática, aunque combinando elementos filosóficos a veces contradictorios, como los que hacen parte del concepto de Estado social de derecho, con elementos propios de la filosofía neoliberal, especialmente relacionados con las libertades económicas y los servicios públicos, que estaba en auge en ese momento. Las relaciones de esa nueva y actual constitución con el derecho administrativo serán objeto de análisis en los siguientes puntos de este trabajo.

Podemos concluir, en general, que frente a los grandes temas tratados por las diferentes constituciones ha sido tradicional el entendimiento de

\footnotetext{
Una completa exposición sobre el contenido de la Constitución Política de Colombia de 1886, incluyendo todas sus reformas, puede consultarse en LUIS CARLOS SÁCHICA, Constitucionalismo colombiano, 9. ed., Bogotá, Editorial Temis, 1988.
} 
que la gran mayoría de ellos constituyen la fuente principal del derecho administrativo en Colombia.

En efecto, si se tiene en cuenta que el derecho público se ha entendido constituido fundamentalmente por el derecho constitucional y el derecho administrativo, se comprende fácilmente que el segundo es el desarrollo del primero, por lo cual siempre se ha entendido que las normas de contenido administrativo, tanto las leyes como los actos administrativos de diversa índole, encuentran su justificación en el objetivo de hacer tangibles y concretos los principios y valores fundamentales del Estado, consagrados en la Constitución. ${ }^{6}$ Por lo mismo, puede afirmarse que si bien es cierto que se trata de ramas del derecho estrechamente ligadas en tanto forman parte del derecho público o del llamado derecho del Estado, y en tanto el derecho administrativo constituye el desarrollo del derecho constitucional, también lo es que las mismas son perfectamente separables y distinguibles, ${ }^{7}$ hasta el punto de que en un buen número de países se ha impuesto su estudio por separado y su distinción tanto desde el punto de vista sustancial como procesal.

\section{La Proyección del Modelo de Estado en el Conjunto del Derecho Administrativo}

La doctrina del derecho constitucional es profusa en el estudio de los diversos aspectos que comprende la "teoría del Estado", pero no ha sido precisa en el establecimiento de un concepto de "modelo de Estado". No obstante, tal concepto es posible deducirlo, circunscribiéndolo a los grandes rasgos o características principales que identifican a un Estado. Desde esa perspectiva, el "modelo" de un determinado Estado puede definirse a partir del estudio, entre otros aspectos, de su vinculación con el derecho, es decir, la forma en que los órganos estatales se vinculan a la legalidad (A); de la concepción política del Estado o la manera en que se estructura jurídica y políticamente (B); de la forma de su gobierno, esto es, la manera en que se encuentran repartidos los poderes públicos dentro de los órganos del Estado $(\mathrm{C})$, y de la manera como se encuentran repartidas las competencias estatales a nivel territorial (D).

\footnotetext{
6 Véase a AGUSTín GORDILLO, Tratado de derecho administrativo, t. I, 5. ed., Buenos Aires, Fundación de Estudios de Derecho Administrativo, 1998, p. VIII-8.

7 Véase a GUIDO ZANOBINI, Curso de derecho administrativo, traducción de la 5. ed., Buenos Aires, Ediciones Arayu, 1954, p. 45 y 46.
}

A \& C R. de Dir. Administrativo \& Constitucional, Belo Horizonte, ano 8, n. 31, p. 124-149, jan./mar. 2008 


\section{A) La vinculación de los poderes públicos a la legalidad}

El Estado liberal de derecho, tanto en la concepción continental, originada en los postulados de la revolución francesa y en el pensamiento de los filósofos del período de la ilustración, y construida por la doctrina alemana alrededor del concepto del rechtsstaat, ${ }^{8}$ como en la de la tradición anglosajona del rule of law, que tiene origen en el Reino Unido, ${ }^{9}$ nace como oposición al Estado absolutista propio de las monarquías europeas, y se caracteriza fundamentalmente porque, de una parte, los poderes públicos y principalmente la administración, quedaron sometidos a la ley y, de otra, los derechos de los ciudadanos fueron reconocidos y protegidos.

Posteriormente, el simple Estado liberal de derecho hizo crisis, dando lugar al llamado Estado constitucional de derecho, cuya existencia se ha extendido en occidente, que introduce como elementos fundamentales el carácter de norma jurídica de la Constitución y la garantía efectiva de los derechos y libertades fundamentales. ${ }^{10}$ Dentro del llamado Estado constitucional de derecho, aparece la modalidad del Estado social de derecho, que incluye la garantía de los derechos sociales y colectivos, y una preocupación mayor por asegurar las condiciones mínimas de vida digna para los ciudadanos, es decir, que el Estado debe involucrarse en la solución de los problemas sociales y no simplemente dejar tal solución al libre juego del mercado. ${ }^{11}$

Desde su nacimiento, Colombia se caracterizó por estructurarse como un Estado de derecho, al menos en el sentido liberal del concepto. En efecto, las diversas constituciones del siglo XIX consagraban el sometimiento de las autoridades públicas al derecho y la garantía de los derechos y libertades individuales. Posteriormente, la consagración del Estado social de derecho en Colombia se introduce a partir de la reforma constitucional de 1936, en la cual se incluye la garantía de los derechos sociales.

En la actualidad, de manera expresa Colombia se encuentra organizado como un Estado social de derecho, no sólo porque así lo dispone el artículo $1^{\circ}$ de la Constitución, sino porque el contexto de la misma impli-

\footnotetext{
8 Sobre la construcción continental, puede verse a OTTO MAYER, Derecho administrativo alemán, t. I, traducción de HEREDIA y KROTOSCHIN, Buenos Aires, Editorial Depalma, 1949, p. 72 y ss.

9 En relación con la construcción anglosajona, véase a WILLIAM WADE and CHRISTOPHER FORSYTH, Administrative Law, $9^{\text {th }}$ ed., London, Oxford University Press, 2004, p. 20 y ss.

10 Sobre el nacimiento y evolución del Estado de derecho, véase a GUSTAVO ZAGREBELSKY, El derecho dúctil. Ley, derechos, justicia, Madrid, Editorial Trotta, 1999, p. 21 y ss.

11 Sobre el Estado social de derecho, véase a ERNESTO BENDA, "El Estado social de derecho", en AAVV. Manual de derecho constitucional, 2. ed., Madrid, Editorial Marcial Pons, 2001, p. 487 y ss.
} 
ca el sometimiento de los poderes públicos al ordenamiento jurídico y garantiza los derechos fundamentales individuales, sociales y culturales.

La circunstancia de que Colombia se encuentre organizada como un Estado social de derecho conlleva incidencias muy importantes para el derecho administrativo: en primer lugar, se consolida la obligación para la administración pública de respetar siempre las reglas de derecho a las que se encuentra sometida, comenzando por la Constitución. Adicionalmente, la existencia de un Estado social de derecho que pretende lograr la existencia de condiciones de vida digna para sus habitantes, demanda de la administración unas mayores responsabilidades, que se traducen en una mayor presencia del Estado y en la necesidad de competencias más dinámicas y efectivas, acompañadas de normas que regulen y garanticen el control de su actividad, todas las cuales forman parte del derecho administrativo.

\section{B) La concepción política del Estado}

Según la doctrina, "las relaciones que unen entre sí los diversos elementos constitutivos de carácter tradicional del mismo Estado -gobierno, pueblo y territorio, sobre la base de concepciones específicas del carácter político - jurídico" dan lugar a diversas concepciones políticas del Estado: el Estado democrático, el Estado socialista y el Estado totalitário. ${ }^{12}$

Frente a estas concepciones, el Estado colombiano tradicionalmente ha sido un Estado democrático. En efecto, salvo durante algunos períodos de gobierno de facto en el siglo XIX, fruto de las diversas guerras civiles que vivió la sociedad colombiana, y de los años 1953 a 1957, la organización del Estado colombiano ha sido democrática. En la actualidad, de conformidad con el artículo $1^{\circ}$ de la Constitución Política, Colombia es un Estado democrático, ya no simplemente representativo sino que el modelo constitucional pregona la aplicación de una democracia participativa fortalecida con la introducción de mecanismos de participación ciudadana distintos al simple voto, como se evidencia en el artículo 103, el cual consagra, además del voto, otros mecanismos de participación ciudadana como el plebiscito, el referendo, la consulta popular, el cabildo abierto, la iniciativa legislativa y la revocatoria del mandato. ${ }^{13}$

\footnotetext{
12 PAOLO BISCARETTI DI RUFFíA, Introducción al derecho constitucional comparado, traducción de la 6. ed. italiana, Bogotá, Fondo de Cultura Económica, 1997, p. 114.
}

A \& C R. de Dir. Administrativo \& Constitucional, Belo Horizonte, ano 8, n. 31, p. 124-149, jan./mar. 2008 
La consagración de la democracia participativa como forma del Estado colombiano también trae importantes consecuencias para el derecho administrativo. En efecto, la participación ciudadana en las decisiones de la administración pública encuentra un espacio cada vez mayor, tanto en la elaboración misma de la decisión como en su control, aumentando con ello la legitimidad de las actuaciones administrativas, pues en los casos en que ella se aplica, dichas actuaciones dejan de ser simplemente unilaterales y mediante la participación de los ciudadanos destinatarios de las mismas se convierten en decisiones consensuadas. ${ }^{14}$ En cuanto al control de la administración pública, éste deja de ser simplemente institucional, es decir, realizado por el mismo Estado, pues el ciudadano, además de los tradicionales instrumentos de control administrativo y judicial, tiene la posibilidad de convertirse en veedor de la actuación administrativa en temas tan trascendentales como el gasto público.

\section{C) La forma del gobierno}

Cuando se habla de la forma de gobierno de un Estado se hace referencia a la manera como se encuentran repartidos los poderes públicos dentro de los órganos del Estado, estableciendo cuál de ellos tiene una cierta preeminencia sobre los otros. La distinción más tradicional de las formas de gobierno se traduce en la división tripartita aristotélica: monarquía, aristocracia y democracia, con sus formas degeneradas de tiranía, oligarquía y demagogia. Sin embargo, frente a regímenes de democracia clásica, resulta más útil tomar en consideración el órgano competente para trazar la dirección política general, como criterio de clasificación, frente a lo cual encontramos tres formas específicas de gobierno: la constitucional pura (monárquica o presidencial), la constitucional parlamentaria (monárquica o republicana) y la constitucional directorial. ${ }^{15}$

Frente a esas formas de gobierno, el régimen constitucional colombiano, desde siempre y aun en la Constitución de 1991, vigente en la actualidad, ha mostrado una fuerte preeminencia del poder ejecutivo,

\footnotetext{
13 Sobre la democracia participativa en Colombia, puede verse a MANUEL JOSÉ CEPEDA, Introducción a la Constitución de 1991, Bogotá, Presidencia de la República, 1993, p. 147 y ss, y a JAIME ARAÚJO RENTERÍA, Principios de derecho constitucional, Bogotá, McGraw Hill, 1999, p. 3 y ss.

14 En relación con los actos administrativos consensuales, véase a LUCIANO PAREJO ALFONSO, Derecho administrativo, Barcelona, Editorial Ariel, 2003, p. 941 y ss.

15 Sobre las diversas formas de gobierno, véase a PAOLO BISCARETTI DI RUFFÍA, ob. cit., p. 153 y ss.
} 
por lo cual ha sido calificado, más que como un régimen simplemente presidencial, como un régimen "preponderantemente presidencialista", como lo ha expresado Jacques Lambert, ${ }^{16}$ influido por los sistemas políticos de España, Estados Unidos y Francia. Las características del régimen presidencial colombiano, dada la muy fuerte preeminencia del poder ejecutivo, han llevado a que se le califique como un sistema presidencialista, en el sentido de constituir una versión acentuada del sistema presidencial de los Estados Unidos. ${ }^{17}$

La reafirmación del sistema presidencial en Colombia mantiene importantes influencias sobre el derecho administrativo, pues la existencia de una preeminencia del poder ejecutivo implica que éste goza de facultades y poderes que amplifican su campo de acción y, en consecuencia, el ámbito de regulación de las normas del derecho administrativo.

\section{D) La repartición de competencias estatales a nivel territorial}

Frente a la distribución del poder en razón de las funciones del Estado, desarrollada por Montesquieu mediante el principio de la separación de poderes, la organización de un Estado también implica plantearse la cuestión de si el ejercicio del poder y de las respectivas funciones públicas se distribuye o no desde el punto de vista territorial. En otras palabras, si el poder se concentra exclusivamente en manos del Estado o si, por el contrario, se distribuye entre él y las diversas comunidades que habitan parte del territorio estatal.

$\mathrm{Al}$ respecto, buena parte de los Estados modernos se encuentran divididos territorialmente, por dos razones principales: por una parte, una razón práctica consistente en la imposibilidad de resolver todos los asuntos del Estado desde el centro y, por otra, una razón política derivada de la existencia de necesidades locales específicas que generan presión sobre el Estado para que les sea permitido a las comunidades locales resolverlas. Dentro de esa división territorial, existen autoridades que gobiernan el Estado en su conjunto, y autoridades que gobiernan las partes o sectores en que se encuentra dividido el territorio del Estado.

La existencia de divisiones territoriales en el Estado y de las corres-

\footnotetext{
16 Véase JACQUES LAMBERT, América Latina, estructuras sociales e instituciones políticas, Barcelona, Ediciones Ariel, 1973 , p. 54 y ss.

17 Sobre el presidencialismo colombiano, puede consultarse nuestro estudio titulado Los actos del ejecutivo en el derecho colombiano, Bogotá, Editorial Temis, 1977, p. 6 y ss.
}

A \& C R. de Dir. Administrativo \& Constitucional, Belo Horizonte, ano 8, n. 31, p. 124-149, jan./mar. 2008 
pondientes autoridades con poder nacional o territorial determina la existencia de las diversas clases de Estado, según que las relaciones entre las divisiones territoriales y el Estado, y entre las autoridades nacionales y territoriales, sean de mayor o menor dependencia o autonomía. Las clases de Estado que resultan de la aplicación de los anteriores criterios son, básicamente, el Estado federal, el Estado unitario y el Estado regional. ${ }^{18}$

En relación con esta perspectiva, es preciso hacer notar que durante el siglo XIX la mayor preocupación en cuanto a la organización del Estado colombiano fue la de si debía adoptarse un sistema federal o unitario. Dadas las circunstancias de todo Estado naciente, en ese siglo fue muy común el cambio constante de la arquitectura constitucional del Estado colombiano, en el sentido de que unas veces Colombia fue organizada como Estado federal (Constituciones de 1853, 1858 y 1863), y otras como Estado unitario (Constituciones de 1821, 1830, 1832, 1843 y 1886). Dentro de esa inestabilidad constitucional, la Constitución de 1886 vino a poner punto final a la discusión de si el Estado colombiano debía ser unitario o federal, al tomar como partido la primera de esas posibilidades de organización, decisión que aun se mantiene.

En efecto, dentro de la configuración constitucional actual, Colombia se encuentra organizada como un Estado unitario, pues el artículo $1^{\circ}$ de la Constitución de 1991, expresa que "Colombia es un Estado social de derecho organizado en forma de República unitaria, descentralizada y con autonomía de sus entidades territoriales". Sin embargo, la lectura y el análisis de esta norma constitucional, permite afirmar que Colombia tampoco es simplemente un Estado unitario, pues aplica fuertes elementos de descentralización territorial y de autonomía de las entidades territoriales, aunque limitada, que atenúan el centralismo dentro del Estado unitario colombiano.

La existencia de un Estado unitario, aunque descentralizado y con autonomía de las entidades territoriales, implica la existencia de estructuras administrativas que responden a esa conformación del Estado. Igualmente implica que será mayor el aparato administrativo en las entidades territoriales en la medida en que las corporaciones públicas seccionales y locales, elegidas popularmente, no forman parte del legislativo sino que

\footnotetext{
18 Para extenderse sobre estas clases de Estado, puede consultarse nuestra obra Estructura del poder público en Colombia, 9. ed., Bogotá, Editorial Temis, 2004, p. 11 y ss.
} 
hacen parte de la administración pública, aunque con cierta autonomía y competencias propias y exclusivas. Además, la conformación del Estado descrita permite desarrollar los llamados instrumentos de atenuación del centralismo, como la descentralización en sus diversas formas, la desconcentración y la delegación.

\section{Principales Principios y Criterios Constitucionales que afectan al Derecho Administrativo}

Como expresión de las relaciones entre el derecho administrativo y el derecho constitucional, que hemos identificado en el acápite I de este trabajo, y del modelo de Estado que ha quedado descrito en el punto II, la Constitución colombiana actual consagra múltiples principios y criterios que, de una u otra forma, se reflejan en el derecho administrativo. Entre esos múltiples principios y criterios podemos identificar, como los más importantes, los siguientes:

1. El principio de la unidad nacional, reflejado en diversas disposiciones constitucionales, a partir del preámbulo y el artículo $1^{\circ}$, según el cual "Colombia es un Estado social de derecho organizado en forma de República unitaria”. Este principio se refleja de manera muy amplia, a su vez, en el conjunto del derecho administrativo, especialmente en el tema de la organización del Estado, que está marcado por el concepto de unidad. Así, por ejemplo, el control judicial de la administración, que está en cabeza de la jurisdicción contencioso administrativa, se ejerce bajo el principio de la unidad nacional, en el sentido de que dicha jurisdicción especial, como toda la rama judicial, está en manos de la nación y no de las entidades territoriales.

2. El principio de la descentralización, también consagrado en el artículo $1^{\circ}$ y que constituye una limitación al principio de la unidad nacional, en la medida en que si sólo se aplicara este último todas las funciones del Estado estarían centralizadas, mientras que el principio de la descentralización permite matizar y racionalizar los efectos del criterio de unidad, por medio del traslado de funciones administrativas a las entidades territoriales y demás "entidades descentralizadas", concepto este último que desde hace varias décadas hajugado un papel importante en el derecho colombiano para referirse a todas aquellas personas jurídicas públicas diferen- 
tes del Estado propiamente dicho.

3. El principio de autonomía de las entidades territoriales, igualmente consagrado en el artículo $1^{\circ}$ de la Constitución, y reflejado en el régimen político y administrativo de estas entidades, contenido en el Título XI de la Constitución y desarrollado en los diferentes estatutos que regulan la vida administrativa de los departamentos, municipios, distritos y áreas metropolitanas. Además, debe tenerse en cuenta que la Constitución de 1991 prevé la existencia, como otras expresiones de la autonomía territorial, de las regiones, provincias y territorios indígenas, que aún no han empezado a funcionar por la ausencia de los estatutos legales y administrativos que desarrollen las correspondientes disposiciones constitucionales. Igualmente, la existencia de esta autonomía se traduce en la consagración constitucional de competencias administrativas que son exclusivas de las entidades territoriales.

4. El principio de la participación, expresado en diferentes normas constitucionales, empezando por el artículo $1^{\circ}$, y reflejado en los mecanismos de participación ciudadana a los que se refieren el Título IV y el capítulo I del título IX, así como en las leyes estatutarias que desarrollan estas normas. Como lo señalamos atrás, el modelo constitucional colombiano consagra una democracia participativa, fortalecida con la introducción de mecanismos de participación ciudadana diferentes del sufragio, como lo son el plebiscito, el referendo, la consulta popular, el cabildo abierto, la iniciativa legislativa y la revocatoria del mandato. El principio de participación se encuentra reforzado con la consagración en el título IX de toda una organización electoral encargada de la aplicación práctica de la participación ciudadana.

5. El principio de prevalencia del interés general, consagrado, entre otros, en los artículos $1^{\circ}, 58$ y 209 de la Constitución, de acuerdo con el cual las decisiones estatales, incluidas las decisiones administrativas, deben tener como finalidad la satisfacción del interés de la comunidad. Para el efecto, la Constitución dota al Estado de instrumentos como la extinción del dominio de bienes adquiridos ilícitamente, la expropiación y la función social y ecológica de la propiedad. Como otra expresión de la prevalencia del interés general, es un deber del Estado la protección del espacio público 
y su destinación al uso común, el cual prevalece sobre el interés particular. Igualmente, en desarrollo de este principio se impone como sanción la nulidad de los actos estatales que lo desconozcan.

6. El principio de la jerarquía normativa, consagrado en el artículo $4^{\circ}$ de la Constitución Política y desarrollado en las normas constitucionales sobre control judicial de la actividad legislativa y administrativa. Este principio parte de la idea de la supremacía de las normas constitucionales y de una consecuente estructura jerarquizada del ordenamiento jurídico, en la cual las normas legales y administrativas siempre deben expedirse, tanto formal como materialmente, de conformidad con las normas superiores. Como desarrollo de este principio, el sistema jurídico colombiano consagra la acción de inconstitucionalidad de las leyes y diversas acciones judiciales contra los actos administrativos. Además, se ha reconocido la posibilidad de ejercer el control constitucional de las normas legales y administrativas por vía de excepción, es decir, a través de la posibilidad de inaplicar esas normas cuando violan el citado principio.

7. El principio de legalidad, consagrado en diversas normas constitucionales, entre ellas el artículo $1^{\circ}$, que se refiere al Estado de derecho, y los artículos $6^{\circ}$ y 121 que prohíben a las autoridades públicas extralimitarse en el ejercicio de sus funciones. Este principio encuentra expresión práctica en la sujeción plena de la administración pública a la legalidad y en su vinculación positiva al ordenamiento jurídico en el sentido de que la administración requiere de habilitación legal previa, es decir, que la acción administrativa debe ser desarrollada según una regla de referencia preestablecida y no de modo arbitrario, de tal manera que no puede existir empleo público que no tenga previamente consagradas funciones detalladas.

8. El principio de la diversidad étnica y cultural de la nación, consagrado en los artículos $1^{\circ}, 7^{\circ}$ y $8^{\circ}$, que reconoce el carácter pluralista del Estado colombiano, específicamente en lo que tiene que ver con los asuntos étnicos y culturales. En efecto, Colombia es un Estado con una multiplicidad de etnias y culturas que conviven en ella y que la Constitución reconoce y protege a través de diversos mecanismos como la participación de las negritudes y los grupos 
indígenas en el Congreso de la República y la existencia de territorios indígenas como entidades territoriales. Todo ello se desarrolla no solo a través de leyes sino de actuaciones administrativas que obligan a la administración pública a enmarcar dentro de ese principio las actuaciones que tienen que ver con esos aspectos étnicos y culturales.

9. El principio de la dignidad humana, consagrado el artículo $1^{\circ}$, conforme al cual Colombia es un Estado... fundado en el respeto de la dignidad humana". Este principio impone obligaciones y restricciones importantes a la actividad del Estado, especialmente de la administración pública, al obligarla a que sus acciones estén orientadas por el mismo, como derecho fundamental.

10. El principio de igualdad, reflejado en diversas disposiciones constitucionales como el preámbulo y el artículo 13, y que se traduce en que las autoridades públicas están obligadas a dar igual trato y protección a las personas, y éstas gozarán de los mismos derechos, libertades y oportunidades, sin discriminación. En el propósito de alcanzar una igualdad material, la administración pública tiene un papel fundamental no sólo en cuanto está obligada a respetar este derecho fundamental sino a realizar acciones positivas tendientes a lograr tal fin.

11. El principio del debido proceso, consagrado en el artículo 29 de la Constitución y que tradicionalmente fue entendido como garantía de los procesados judicialmente. Sin embargo, la Constitución de 1991 dejó claro que el "debido proceso se aplicará a toda clase de actuaciones judiciales y administrativas". En consecuencia, la administración, siempre que adelante un procedimiento administrativo, estará en el deber de seguir rigurosamente las ritualidades establecidas en las normas jurídicas que constituyen una garantía del ciudadano frente al poder de la administración.

12. El principio de protección de los derechos y libertades fundamentales, que se desprende del Título II de la Constitución bajo la idea de que no basta la consagración expresa de los derechos y libertades fundamentales, sino que es preciso que existan instrumentos para lograr su verdadera efectividad. Así, la Constitución consagra las acciones de tutela, de cumplimiento, populares y de grupo, como medios judiciales especiales para hacer efectivos esos derechos. 
13. El principio del respeto de los derechos adquiridos, consagrado en el artículo 58 de la Constitución. Este principio obliga a la administración a que con sus actuaciones no desconozca los derechos adquiridos por los particulares con arreglo a las leyes. Como desarrollo de este principio, la misma norma, en aplicación del principio de prevalencia del interés general, autoriza la expropiación por vía judicial y administrativa, pero impone como carga a la administración el deber de indemnizar los daños que una actuación de esta clase pueda generar a un particular titular de un derecho adquirido.

14. El principio de protección de los bienes públicos, reflejado en diversas normas constitucionales, especialmente en los artículos 63, 72 y 75, que hacen inalienables, imprescriptibles e inembargables los bienes de uso público, los parques naturales, las tierras comunales de los grupos étnicos, el patrimonio arqueológico y cultural de la Nación y el espectro electromagnético. Igualmente, en virtud de este principio, es deber del Estado velar por la protección del espacio público y su destinación al uso común. Todo ello se desarrolla a través de diversas normas legales y reglamentaciones administrativas.

15. El principio de la responsabilidad del Estado y sus servidores, reflejado en diversas normas constitucionales, en especial el artículo 90, erige en obligación del Estado y de sus servidores la reparación de los daños antijurídicos que sus actuaciones generen, lo cual constituye el fundamento de uno de los capítulos más importantes del derecho administrativo, como es el de la responsabilidad pública.

16. El principio de la separación de poderes, consagrado en el artículo 113 y desarrollado en los Título V a XI, conforme al cual el poder del Estado colombiano se encuentra dividido entre las ramas legislativa, ejecutiva y judicial, pero además existen otros órganos autónomos e independientes que cumplen las demás funciones del Estado. No obstante la existencia de esta separación, la misma norma constitucional aclara que las ramas y órganos del poder público, para lograr la realización de los fines del Estado, deben actuar armónicamente entre sí bajo el principio de colaboración. Como se comprende fácilmente, este principio se refleja en todo el tema de la organización administrativa, que es otro de los capítulos fundamentales del derecho administrativo. 
17. El principio de carrera administrativa, consagrado en el artículo 125 de la Constitución Política, de conformidad con el cual, como regla general, los empleos en los diversos órganos y entidades estatales deben proveerse por el sistema de concurso público, de tal manera que los funcionarios ingresen al servicio y puedan ascender en la jerarquía administrativa por méritos y su retiro sólo pueda darse por causas legales. El desarrollo de este principio da lugar a todo un capítulo del derecho administrativo que es el de la función pública.

18. Los principios de la función administrativa, consagrados expresamente en el artículo 209 de la Constitución, de acuerdo con el cual esta función está al servicio de los intereses generales y debe desarrollarse con fundamento en los principios de igualdad, moralidad, eficacia, economía, celeridad, imparcialidad y publicidad. Estos principios se reflejan en otras normas constitucionales y se desarrollan en los diferentes estatutos legales que regulan el ejercicio de la función administrativa. Tal es el caso, por ejemplo, de los artículos 23 y 74 de la Constitución que consagran los derechos de petición y de acceso a los documentos públicos, los cuales son expresión del principio de publicidad de la función administrativa y se encuentran desarrollados en el Código Contencioso Administrativo.

19. El principio de control de la actividad administrativa, consagrado en diversas disposiciones constitucionales como el Capítulo 3 del Título VIII y el Título X. Este principio se refiere, en primer lugar, al control judicial de la actividad administrativa, por medio de una jurisdicción especializada en el juzgamiento de las actuaciones de la administración pública. Además, la Constitución hace especial énfasis en los controles administrativos, a través del control disciplinario y el control fiscal. Finalmente, en concordancia con el principio de participación, la Constitución prevé un control interno y un control ciudadano de la actividad administrativa, los cuales son desarrollados por la ley.

20. El principio de la libertad económica, consagrado en el artículo 333 bajo la idea de que la libertad económica y la iniciativa privada son libres dentro de los límites del bien común. La misma disposición constitucional le impone como obligación al Estado la de 
promover la libre competencia y la de realizar acciones para impedir restricciones en tal libertad y abusos en la posición dominante del mercado nacional. Igualmente, la exigencia de permisos y otros requisitos previos sólo podrá hacerse en la medida en que la ley así lo disponga.

21. El principio de intervención del Estado en la economía, consagrado en los artículos 333 y 334, parte de la aceptación de la libertad económica de los particulares, pero impone al Estado la dirección general de la economía, para lo cual podrá intervenir en la explotación de los recursos naturales, en el uso del suelo, en la producción, distribución y consumo de los bienes y servicios, con el fin de racionalizar la economía y de lograr el mejoramiento de la vida de los habitantes, la distribución equitativa de las oportunidades y la preservación de un ambiente sano. En este deber y facultad de intervención del Estado en la economía tiene un papel preponderante la administración, en la medida en que es la rama del poder público que tiene el deber de adelantar las acciones concretas para lograr las finalidades para las que está concebida esta intervención.

22. El principio de la planeación, consagrado en el Capítulo 2 del Título XII, se refiere a que toda la actividad del Estado, pero especialmente la actividad de la administración pública, debe realizarse de acuerdo con un plan de desarrollo que incluye propósitos y metas de largo y mediano plazo, y presupuestos plurianuales. Esta obligación de planeación no se limita al nivel nacional sino que las entidades territoriales también deben ajustarse a sus propios planes de desarrollo. Finalmente, teniendo en cuenta que la administración pública es la principal destinataria del plan, el ejecutivo tiene el mayor protagonismo en su elaboración y puede llegar, inclusive, a ser el competente para su aprobación cuando el legislador no lo hace oportunamente.

23. El principio de legalidad del gasto público, consagrado en el Capítulo 3 del Título XII, de conformidad con el cual el Estado sólo podrá realizar erogaciones con cargo al tesoro público y percibir impuestos y contribuciones que se encuentren previamente considerados en el presupuesto anual, el cual deberá estar de acuerdo con los planes nacionales de desarrollo. En consecuencia, la administración no es 
libre para la ejecución del gasto público sino que, por el contrario, se encuentra limitada por las disposiciones que al respecto hayan sido consignadas en el respectivo presupuesto anual. Este principio es desarrollado por la ley a través de un completo estatuto que regula la actividad de la administración en esta materia.

24. El principio del acceso de todos a la prestación eficiente de los servicios públicos, consagrado en el capítulo 5 del Título XII. Este principio se refiere a que, de una parte, es deber del Estado asegurar la prestación eficiente de los servicios públicos, ya sea directa o indirectamente, por comunidades organizadas, o por particulares y, de otra, que todos los habitantes tienen derecho a acceder a ellos. Este principio se desarrolla por medio de los estatutos que regulan la prestación de los diferentes servicios y que constituyen el objeto de una parte muy importante del derecho administrativo.

\section{Las Instituciones del Derecho Administrativo que han sido elevadas a rango constitucional}

La Constitución colombiana de 1991 presenta como uno de sus rasgos característicos el ser calificada de "reglamentarista". Este calificativo precisamente ha querido señalar la circunstancia de que es una Constitución que no solo consagra principios y normas generales, como ha sido la filosofía que ha inspirado la mayoría de las constituciones de los diversos países, sino que en su redacción ha llegado a incluir normas detalladas, propias más bien de las disposiciones que deben desarrollar la Constitución.

Esa circunstancia ha facilitado el que diversas instituciones públicas, que hasta antes de la Constitución de 1991 tenían apenas reconocimiento legal o simplemente administrativo, hayan sido elevadas a rango constitucional.

En ese orden de ideas, encontramos un primer grupo de principios e instituciones que ya estaban presentes en la Constitución de 1986 y que la Constitución de 1991 vino simplemente a ratificar. Tal es el caso de principios como el de la unidad nacional o el carácter democrático y republicano del Estado. Lo mismo sucede con algunos derechos y libertades, como la libertad individual y la garantía del respeto a los derechos adquiridos, que ya se encontraban consagrados y vinieron a ser ratificados. Lo propio ocurre con diversas instituciones de la organización del Estado, resultantes de la aplicación del principio de la separación de poderes que fueron ratificadas por la Constitución de 1991 con algunas

A \& C R. de Dir. Administrativo \& Constitucional, Belo Horizonte, ano 8, n. 31, p. 124-149, jan./mar. 2008 
precisiones. Finalmente, en relación con el régimen económico y de hacienda pública, también encontramos principios e instituciones ratificados, como el deber de realizar presupuestos anuales y de ajustar el gasto público a ellos, que ya se encontraba consagrado en la Constitución de 1886. Obviamente, en relación con estos principios e instituciones no puede hablarse de elevación a rango constitucional en la medida en que ellos, de una u otra forma, estaban consagrados y contenidos en la constitución anterior.

Otros principios e instituciones incluidos en la Constitución de 1991 también ya estaban consagradas en la Constitución de 1886, pero con una visión o contenido diferente, por lo cual tampoco podemos hablar propiamente de elevación a rango constitucional sino, más bien, de transformación en su concepción. Tal es el caso, por ejemplo, del Estado social de derecho, consagrado como uno de los pilares de la Constitución de 1991, que tradicionalmente venía consagrado en las constituciones anteriores como simple "Estado de derecho", al cual se le habían agregado, poco a poco, algunos deberes sociales.

Pero no hay duda de que otros principios e instituciones consagrados en la Constitución de 1991 lo fueron de manera novedosa en ella. Algunas porque no existían en el derecho colombiano, como la consagración de ciertos derechos y las acciones de tutela, de cumplimiento, populares y de grupo para su garantía. Pero otros aparecen como novedosos no necesariamente porque no existieran en la vida institucional de Colombia, sino porque su consagración era apenas legal o reglamentaria, por lo cual, respecto de ellos, puede hablarse efectivamente de su elevación a rango constitucional.

Así, frente a los grandes temas que están regulados en la Constitución de 1991, podemos identificar, los siguientes principios e instituciones que han sido objeto de elevación a rango constitucional, sin que esta identificación sea taxativa, en virtud de las limitaciones de extensión de este trabajo:

\section{A) En cuanto a los principios fundamentales}

La Constitución de 1991, además de incluir en su preámbulo un buen número de principios y valores, dedica su Título I a los Principios Fundamentales que rigen la vida institucional del país. En este grupo encontramos los siguientes principios que no aparecían mencionados en la Constitución anterior pero que tenían algún reconocimiento en las leyes o en reglamentaciones administrativas:

A \& C R. de Dir. Administrativo \& Constitucional, Belo Horizonte, ano 8, n. 31, p. 124-149, jan./mar. 2008 
El reconocimiento de la diversidad étnica y cultural se consagra expresamente como uno de los principios fundamentales en los que se encuentra fundado el Estado colombiano. Este reconocimiento existía en el ordenamiento jurídico en instituciones como los resguardos indígenas, que eran objeto de diversas regulaciones, pero como fruto del debate pluralista que dio lugar a la Constitución Política de 1991, mereció ser elevado a categoría constitucional, específicamente en el artículo $7^{\circ}$ de la Constitución.

Lo propio ocurrió con la protección de las riquezas culturales y naturales de la nación, la cual también encontraba reconocimiento en normas dispersas del ordenamiento colombiano, como las leyes que protegían el patrimonio histórico de la nación así como las normas sobre explotación de los recursos naturales renovables y no renovables, pero el artículo $8^{\circ}$ de la Constitución vino a elevar a categoría constitucional ese deber estatal.

En cuanto al principio de la integración latinoamericana y del Caribe, resulta evidente que con ocasión de los diversos tratados de integración suscritos y ratificados por Colombia con anterioridad a 1991, como el Acuerdo de Cartagena de 1968, que reunió a los países del área andina como un mercado común, se pretendía tal integración como un propósito nacional. Sin embargo, recogiendo este propósito, el artículo $9^{\circ}$ de la Constitución erige la integración con estas áreas como uno de los principios fundamentales del Estado colombiano.

Finalmente, en lo que hace a los idiomas oficiales de Colombia, con anterioridad a la Constitución de 1991 resultaba evidente que el castellano se utilizaba como el idioma oficial, al punto que las normas procesales así lo disponían expresamente. El artículo $10^{\circ}$ de la Constitución de 1991 erigió como principio fundamental el uso del castellano como idioma oficial, pero reconociendo también las lenguas y dialectos de los grupos étnicos como oficiales en sus territorios, al mismo tiempo que consagró como deber la enseñanza bilingüe en las comunidades con tradiciones lingüísticas propias.

\section{B) En cuanto a los derechos, garantías y deberes}

La carta de derechos y libertades de 1991, contenida en el Título II de la Constitución, constituye una ampliación muy importante en relación con la que contenía la Constitución Política de 1886. Esta nueva carta de derechos y libertades responde, en muchos casos, al cumplimiento de compromisos internacionales de derechos humanos adquiridos por Colombia por medio de la suscripción de tratados durante la segunda mitad del siglo

A \& C R. de Dir. Administrativo \& Constitucional, Belo Horizonte, ano 8, n. 31, p. 124-149, jan./mar. 2008 
XX. Los derechos y libertades protegidas aumentaron especialmente en lo referente a los derechos sociales y colectivos, e igualmente se consagraron mecanismos judiciales de protección efectiva de los derechos y libertades consagrados.

En relación con instituciones propias del derecho administrativo, la Constitución de 1991 elevó a rango constitucional algunas de ellas que con anterioridad se encontraban consagradas en la ley. Así, en primer lugar, como ya tuvimos ocasión de expresarlo, el artículo 29 consagra el derecho al debido proceso, incluyendo expresamente la previsión de que tal derecho se aplique a toda clase de actuaciones administrativas. Este debido proceso administrativo se encontraba previamente consagrado en el Código Contencioso Administrativo como uno de los principios que debían seguirse en las actuaciones administrativas, pero por su importancia el constituyente de 1991 quiso elevarlo a rango constitucional con la categoría de derecho fundamental.

Otra de las instituciones relevantes para el derecho administrativo, que fue elevada a rango constitucional, fue el principio general de la buena fe. Tal principio se encontraba consagrado en las normas de derecho privado, como el Código Civil y el Código de Comercio, y la jurisprudencia lo había considerado un principio general del derecho. El artículo 83 de la Constitución Política de 1991 consagró su existencia y deber de aplicación, extendiéndolo al punto de establecer la presunción de la buena fe en las actuaciones de los particulares ante las autoridades públicas.

La responsabilidad del Estado y de sus servidores fue reconocida y desarrollada en Colombia pretorianamente por la jurisprudencia civil y administrativa desde finales del siglo XIX. Pero el constituyente de 1991, al reconocer la importancia de esta institución, decidió elevarla a rango constitucional, estableciendo en el artículo 90 que el Estado y sus servidores son responsables por los daños antijurídicos causados por sus actuaciones.

Finalmente, en cuanto a la protección del patrimonio público, diversas normas de categoría legal se referían a las diferentes clases de bienes públicos, sus características jurídicas y su protección. La Constitución de 1991 quiso hacer énfasis en la importancia de tales bienes y en los artículos 63, 72 y 75 dispuso que los bienes de uso público, los parques naturales, las tierras comunales de los grupos étnicos, el patrimonio arqueológico y cultural de la Nación y el espectro electromagnético son inalienables, imprescriptibles e inembargables. Así mismo, se erigió a categoría constitucional el concepto de espacio público y el deber de su protección por 
parte del Estado.

\section{C) En cuanto a la organización del Estado}

En este tema, que es el de mayor extensión en su tratamiento por la Constitución de 1991, encontramos el mayor número de ejemplos de instituciones del derecho administrativo elevadas a rango constitucional.

En este sentido podemos citar como ejemplo indiscutible el de la llamada en la Constitución de 1991 "organización electoral”, conformada por el Consejo Nacional Electoral y la Registraduría Nacional del Estado Civil, que hoy constituyen órganos autónomos e independientes de las ramas del poder público y que tienen a su cargo la organización, dirección y vigilancia de las elecciones y lo relativo a la identificación de las personas. Se trata de un típico caso de elevación a rango constitucional, pues estas instituciones existían en el régimen anterior, pero no por consagración constitucional sino por reconocimiento de carácter legal, y se consideraba que hacían parte, aunque con cierto grado de autonomía, de la rama ejecutiva del poder público.

Otro ejemplo de elevación de instituciones del derecho administrativo a rango constitucional está dado por el reconocimiento y regulación del Banco de la República en la Constitución de 1991. En efecto, esta entidad, que viene ejerciendo en Colombia las funciones de banca central, fue creada desde 1923, con la finalidad de manejar la política monetaria y a partir de ese momento fue adquiriendo mayor importancia, lo cual se reflejó en la expedición de diversas leyes que periódicamente la transformaban y fortalecían. Sin embargo, hasta antes de la Constitución de 1991 se le consideraba como una institución administrativa, perteneciente a la rama ejecutiva, a pesar de que su proceso de fortalecimiento llegó hasta el punto de ser considerada "entidad de naturaleza única". La Constitución de 1991, como uno de los efectos de su especial preocupación por regular lo atinente al régimen económico y la hacienda pública, elevó a rango constitucional a esta entidad, reconociéndole autonomía especial y fortaleciendo y reconociendo sus funciones en el propio texto constitucional.

El régimen de los servidores públicos, a través de sistema de carrera administrativa, que conlleva su selección por medio de concurso público de acuerdo con los méritos, y su permanencia y retiro de acuerdo con una regulación propia, es otro de los típicos ejemplos de instituciones del derecho administrativo que se elevaron a rango constitucional. En efecto, en

A \& C R. de Dir. Administrativo \& Constitucional, Belo Horizonte, ano 8, n. 31, p. 124-149, jan./mar. 2008 
vigencia de la Constitución de 1886, específicamente desde 1938, se intentó en Colombia la aplicación de una carrera administrativa y, posteriormente, diversas normas pretendieron dar aplicación práctica a este sistema. La Constitución de 1991, en aras de la tecnificación y despolitización de los empleos públicos, ordenó que éstos fueran proveídos, por regla general, por el sistema de carrera administrativa, con fundamento en los méritos de los aspirantes a dichos empleos, y elevó a categoría constitucional las bases para la aplicación de este sistema.

En cuanto a los principios que regulan el ejercicio de la función administrativa, que son de capital importancia para el derecho administrativo, la mayoría se encontraban previstos en diversas normas, especialmente en el Código Contencioso Administrativo. A este respecto, la Constitución de 1991 ratificó su existencia y elevó a categoría constitucional el deber de aplicación de varios de esos principios, como los ya mencionados de igualdad, moralidad, eficacia, economía, celeridad, imparcialidad y publicidad.

Finalmente, los mecanismos de atenuación del centralismo habían sido desarrollados legalmente desde antes de 1991. Así, en la normatividad legal que regulaba la organización de la administración pública se contemplaba ya la descentralización administrativa, la delegación y la desconcentración de funciones. A este respecto, si bien podría decirse que en las últimas reformas de la Constitución de 1886 se encontraban tácitamente reconocidos estos conceptos, la Constitución de 1991, al reconocer la importancia, dispuso expresamente que la función administrativa debe ser ejercida mediante la utilización de esos mecanismos y llegó hasta reglamentar diversos aspectos de los mismos, como es el caso de la responsabilidad del delegante y el delegatario en materia de delegación, así como otros temas referentes a la descentralización por servicios y por colaboración.

\section{D) En cuanto al régimen económico y la hacienda pública}

Como lo expresamos en el acápite anterior, la Constitución de 1991 se preocupó de manera especial por el régimen económico y la hacienda pública, hasta el punto de dedicar a ese tema un gran Título (el Título XII), conformado por 42 artículos y dividido en seis capítulos, frente al tratamiento que le daba la Constitución de 1886, en la cual apenas existía un pequeño Título conformado por 12 artículos.

Como podrá comprenderse, lo anterior implica que además de la constitucionalización del Banco de la República como institución, también se elevaron a categoría constitucional diversos principios y disposiciones que A \& C R. de Dir. Administrativo \& Constitucional, Belo Horizonte, ano 8, n. 31, p. 124-149, jan./mar. 2008 
antes tenían apenas consagración legal y administrativa. Esos principios y disposiciones tienen que ver especialmente con los planes de desarrollo, el presupuesto, la distribución de recursos y competencias entre la nación y las entidades territoriales y los servicios públicos, temas todos ellos que si bien estaban mencionados en la Constitución anterior, en la de 1991 son objeto de desarrollos y regulaciones precisas, muchas de las cuales estaban consagradas desde antes en estatutos de categoría simplemente legal o administrativa.

Así, por ejemplo, en relación con los planes de desarrollo, si bien la Constitución de 1886 ya consagraba esta institución como obligatoria para el funcionamiento de la administración pública, su aplicación había sido muy parcial, algunas veces por ausencia de regulaciones precisas y otras por falta de fuerza de esas regulaciones. Ante esa situación, la Constitución de 1991 vino a consagrar, en los artículos 339 a 344 diversos aspectos de esta institución, muchos de los cuales contienen disposiciones que deberían ser más de carácter legal y administrativo que constitucional.

Respecto del presupuesto, la Constitución de 1991 recogió el contenido de las disposiciones que venían de la Constitución de 1886, pero, a su vez, añadió un buen número de otras, varias de las cuales ya estaban incluidas en el estatuto legal que regula la preparación, aprobación y ejecución del presupuesto o podrían hacer parte de él, sin necesidad de consagración constitucional. Tal es el caso, por ejemplo, de la norma que ordena la creación del cargo de contador general, como funcionario de la rama ejecutiva, encargado de llevar la contabilidad general de la nación.

En el tema de la distribución de los recursos y competencias se ratifica el deber que ya existía en normas de la constitución anterior de que el Estado central y los entes territoriales tuvieran las competencias plenamente definidas y que para el ejercicio de tales competencias se les asignaran los recursos necesarios. Pero, además, también en este tema la Constitución de 1991 incluye una serie de aspectos de detalle que estaban ya consagrados en estatutos legales o que bien podrían estar en ellos.

Finalmente, en cuanto hace al tema de los servicios públicos, la Constitución elevó a rango constitucional el estado de la evolución de ese tema en el derecho administrativo. En efecto, prevé la Constitución que los servicios públicos pueden ser prestados por los particulares o por el mismo Estado, directa o indirectamente, pero que la regulación, control y vigilancia de los mismos es una función estatal exclusiva. A ello también agrega diversos 
aspectos, algunos de los cuales, como en los temas anteriores, ya estaban consagrados en diversas normas legales y reglamentarias que regulaban desde antes la prestación de algunos servicios públicos.

\section{Conclusiones}

Las reflexiones anteriores nos permiten plantear las siguientes conclusiones sobre el tema cuya presentación nos hemos propuesto:

1. Las relaciones entre el derecho constitucional y el derecho administrativo resultan evidentes en tanto que el segundo encuentra su fuente principal en el primero. Es así como puede afirmarse que la gran mayoría de los temas tratados por las diversas constituciones son objeto de desarrollo por normas que conceptualmente hacen parte del derecho administrativo. Sin embargo, como es obvio, esa relación formal entre las dos ramas del derecho solo puede predicarse a partir del momento en el cual, en cada país, pueda hablarse de la existencia de un derecho administrativo propiamente dicho. En ese sentido, podemos afirmar que en Colombia las relaciones entre el derecho constitucional y el derecho administrativo pueden identificarse a partir de la expedición de la Constitución de 1886 y de la creación de la jurisdicción contencioso administrativa a comienzos del siglo XX, época a partir de la cual puede decirse que realmente existe el derecho administrativo colombiano.

2. El modelo del Estado colombiano se concreta en la existencia de un Estado social de derecho, de carácter democrático y participativo, con un régimen presidencialista y organizado bajo la forma unitaria, aunque descentralizado y con autonomía relativa de sus entidades territoriales. La adopción de este modelo genera consecuencias importantes sobre el derecho administrativo, en la medida en que la mayoría de los grandes temas constitucionales se proyectan en el contenido de este derecho, de lo cual resulta una especial amplitud de los poderes, competencias y responsabilidades de la administración pública y, por lo mismo, un campo de acción creciente para esta rama del derecho.

3. La revisión sistemática del contenido de la Constitución Política de Colombia permite identificar la existencia de múltiples principios que afectan el contenido del derecho administrativo, en la medida en que este último es un desarrollo de aquellos principios 
y que, por lo tanto, sus disposiciones están sometidas al marco de los mismos.

4. La Constitución colombiana actual incluye normas detalladas y específicas sobre diversos temas, lo cual ha favorecido que algunos principios e instituciones propios del derecho administrativo hayan sido elevados a rango constitucional. Esta constitucionalización de principios e instituciones se ha producido en algunos casos porque la Constitución ha querido reconocer especial importancia al respectivo principio o institución. Sin embargo, en otros casos no se encuentra justificación suficiente para la inclusión en la Constitución de principios e instituciones que ya estaban consagrados en normas simplemente legales o que no requieren de reconocimiento constitucional, por lo cual la actual Constitución ha sido calificada de "reglamentarista".

Informação bibliográfica deste texto, conforme a NBR 6023:2002 da Associação Brasileira de Normas Técnicas (ABNT):

RODRÍGUEZ RODRÍGUEZ, Libardo. El Marco Constitucional del Derecho Administrativo en Colômbia. A\&C Revista de Direito Administrativo e Constitucional, Belo Horizonte, ano 8, n. 31, p. 124-149, jan./mar. 2008. 